\title{
Three Different Doses of Intrathecal Morphine as Part of a Multimodal Regimen for Post-Cesarean Delivery Analgesia: A Randomized Double-Blinded Trial
}

\author{
Marcio Luiz Benevides*, Rubens Jardim Nochi Jr., Carlos Eduardo Solcia, \\ Valter Moreira Xavier Júnior, Adalberto Francisco Buss Lima
}

Department of Anesthesiology, Hospital Geral Universitário, Cuiabá, Brazil

Email: *mmmmb@terra.com.br

How to cite this paper: Benevides, M.L., Nochi Jr., R.J., Solcia, C.E., Xavier Júnior, V.M. and Lima, A.F.B. (2018) Three Different Doses of Intrathecal Morphine as Part of a Multimodal Regimen for PostCesarean Delivery Analgesia: A Randomized Double-Blinded Trial. Open Journal of Obstetrics and Gynecology, 8, 780-789. https://doi.org/10.4236/ojog.2018.89081

Received: March 11, 2018

Accepted: July 29, 2018

Published: August 2, 2018

Copyright $\odot 2018$ by authors and Scientific Research Publishing Inc. This work is licensed under the Creative Commons Attribution International License (CC BY 4.0).

http://creativecommons.org/licenses/by/4.0/

\begin{abstract}
Brazil is one of the countries that carry out cesarean delivery in the world. The pain after cesarean delivery (CD) is one of the main concerns of parturient. Intrathecal Morphine (ITM) is widely used for the treatment of pain after CD; however, the optimal dose with minimal side effects is to be established. Objectives: To compare the analgesia and side effects resulted by three different doses of ITM as part of a multimodal regimen for postcesarean delivery analgesia. Methods: One hundred ninety-four patients were sampled in this randomized, double-blinded, three-arm study (group 0.075: ITM $0.75 \mathrm{mg}$; group 0.1: ITM $0.1 \mathrm{mg}$ and group 0.15: ITM $0.15 \mathrm{mg}$ ). All patients received intravenous dexamethasone, dipyrone and ketoprofen. The primary endpoint was pain intensity measured at rest and on movement, while the secondary endpoint was overall satisfaction with pain relief, the incidence of nausea and vomiting, intensity of pruritus, and the use of additional tramadol, antipruritic and antiemetic use within 24 hours after postoperation. Results: The three groups showed similar pain intensity at rest and on movement. The pain intensity on movement was significantly higher than at rest in the groups $(\mathrm{p}<0.001)$. There were no significant differences among the groups regarding secondary endpoint. Conclusions: Our findings suggest that in cases of an elective CD, $0.075 \mathrm{mg}$ of ITM produces postoperative analgesia of similar quality that provided by 0.1 or $0.15 \mathrm{mg}$ ITM. The patients should have a multimodal analgesia approach that includes: ITM, anti-inflammatory agents and access to additional systemic analgesic if necessary.
\end{abstract}

\section{Keywords}

Spinal Anesthesia, Cesarean Delivery, Intrathecal Morphine, Postoperative 
Pain, Multimodal Analgesia

\section{Introduction}

The cesarean delivery (CD) rate has been increased in Brazil, reaching $55.5 \%$ in 2015 (around 1.8 million operations) [1], which puts Brazil as one of the countries that carry out cesarean delivery in the world [2].

The spinal anesthesia is the anesthetic technique most often used in elective $\mathrm{CD}$ or emergency situations [3]. Spinal anesthesia offers many advantages for the $\mathrm{CD}$, due to the simplicity of technique, the speed in the administration, to have a fast onset of action and produce intense sensorial and motor neural blockade [4]. The bupivacaine is the local anesthetic of choice [5]. Because of the application of small dose, there is little risk of toxicity by anesthetic for pregnant and drug transfer to the fetus. Besides, the failure of the blockade and the need for conversion to general anesthesia is infrequent [6].

The pain in postoperative CD is one of the main concerns of women [7]. Intrathecal Morphine (ITM) is widely used for the treatment of pain after CD [3] [8]. After administration, it has a slow onset of action and long duration of action (12 to $48 \mathrm{~h}$ ) [9]. In particular, ITM leads to significant cost savings for the first 24 hours when compared with intravenous opioid patient-controlled analgesia [10]. A large part of the studies found in the literature, using ITM doses ranging from 0.1 to $0.25 \mathrm{mg}$ [8].

In our study, we use smaller doses of ITM between 0.07 and $0.08 \mathrm{mg}$, motivated by the concern that higher doses may increase the adverse effects such as nausea, vomiting, pruritus and especially respiratory depression because of the difficulty of monitoring by the nursing team after surgery [11]. However, it is possible that this practice does not provide adequate analgesia, given the observation that many mothers complained of pain of moderate to severe intensity, observed in a pilot study conducted recently in our study. The objective of this study is to compare the analgesia and side effects resulted by three different doses of ITM as part of a multimodal regimen for post-cesarean delivery analgesia.

\section{Methods}

This study was approved by Institutional Ethics Committee of Hospital Geral Universitário, Cuiabá, Brazil (protocol 561.054/2014). It had got written consent from all patients. During the period from August 2014 to October 2015, the patients aged $\geq 18$ years and American Society of Anesthesiologists (ASA) physical status class I to III, and scheduled to undergo elective cesarean section were eligible to participate in this prospective, randomized, controlled, double-blinded study. It excluded patients with body mass index $\geq 40 \mathrm{Kg} / \mathrm{m}^{2}$, the patients refused to participate in the research, contraindication to spinal anesthesia, chronic use of opioid analgesics, and use of illicit drugs, psychiatric disease, allergy 
drugs used in the protocol, conversion to general anesthesia.

Randomization lists were computer-generated. In the operating room, sealed envelopes containing the groups were opened. In this manner, patients were randomized to receive one of three ITM regimens: Group 0.075 (control): morphine $0.075 \mathrm{mg}$, Group 0.1: morphine $0.1 \mathrm{mg}$ or Group 0.15: morphine $0.15 \mathrm{mg}$. The different doses of morphine were diluted in a solution of sodium chloride $0.9 \%$ for completing a total volume of $1 \mathrm{ml}$. The anesthesiologist was preparing the spinal anesthetic mixture, patient, surgeons, and the investigators taking measures and other health care providers, including the post-anesthesia care unit (PACU) and postpartum nurses who administered supplemental analgesic drugs, were blinded to group assignment. Every patient was monitored with electrocardiography, peripheral oxygen saturation, and noninvasive arterial pressure throughout the anesthetic-surgical procedure and received a bladder catheter, which was removed in 12 hours after the operation. It infused 500 to $750 \mathrm{ml}$ of Ringer's lactate (RL) solution before subarachnoid puncture and 10 $\mathrm{mL} \cdot \mathrm{kg}^{-1} \cdot \mathrm{h}^{-1}$ of the same solution until the end of the operation. The subarachnoid puncture was performed with the patient in a sitting position or lateral decubitus in interspaces L3-L4 or L4-L5 with Quincke needle 27G. First was to apply the solution of hyperbaric bupivacaine $12.5 \mathrm{mg}(2.5 \mathrm{ml})$ at the rate of $1 \mathrm{ml}$ in 15 seconds, and then applied $1 \mathrm{ml}$ of the solution containing morphine. Immediately after application of this solution, the patient was placed in the supine position. It applied $3 \mathrm{~L} / \mathrm{min}$ of oxygen via a nasal catheter. Manual displacement of the uterus to left was applied to each patient until the birth of the fetus. After adequate spinal anesthesia was established, cesarean section was allowed to proceed. All the women should undergo through a Pfannenstiel incision and transversal hysterotomy with the closure of visceral and parietal peritoneum. It applied IV fentanyl (maximum $100 \mu \mathrm{g}$ ) to provide analgesia if the patient requested intraoperatively. Decrease in blood systolic pressure $<100 \mathrm{mmHg}$ or $<20 \%$ of baseline value was treated with a bolus of 5 to $10 \mathrm{mg}$ of ephedrine and decrease in heart rate drop $<50$ beats per minute was treated with a bolus of $0.5 \mathrm{mg}$ of atropine. After the clamping of the umbilical cord applied IV cefazolin $2 \mathrm{~g}$, dexamethasone $10 \mathrm{mg}, 5 \mathrm{IU}$ in bolus and $10 \mathrm{IU}$ oxytocin diluted in $500 \mathrm{ml}$ of RL solution. And at the end of the operation it was given with IV ondansetron $4 \mathrm{mg}$, dipyrone $2 \mathrm{~g}$ and ketoprofen $100 \mathrm{mg}$. Dipyrone $2 \mathrm{~g}$ and ketoprofen were maintained every 4 hours and 12 hours, respectively. At the end of the operation the patient would be transferred to the post-anesthesia care unit (PACU). The discharge of PACU occurred when the patient has reached $>9$ scale score Aldrete-Kroulik [12]. The patient's vital signs and respiratory depression (defined as respiratory rate less than 10 breaths per minute) was monitored every one hour for the first 6 hours and once every 2 hours for the next 18 hours. If the patient requested treatment for pain, in the postoperative period, the patient would receive IV tramadol $100 \mathrm{mg}$ diluted in $100 \mathrm{ml}$ of saline solution. Nausea and vomiting (PONV) were treated with ondansetron $4 \mathrm{mg}$ or metoclopramide 10 
$\mathrm{mg}$ IV, and moderate/severe pruritus was treated with promethazine $12,5 \mathrm{mg}$ intramuscularly.

The primary endpoint of the study was the pain intensity measured at rest and on movement (moving from supine to sitting on the bed) at 6 hours and 24 hours. The pain intensity was reported by the patient using an 11-point numeric rating scale (NRS) with the anchors "no pain" $=0$ and "worst pain ever" $=10$ [13]. Secondary endpoint was tramadol use; the overall satisfaction with pain relief was assessed as $0=$ very unsatisfied, $1=$ unsatisfied, $2=$ satisfied, or $3=$ very satisfied; pruritus was assessed using a 4 point score: $0=$ absent, $1=$ mild pruritus, 2 = moderate pruritus, or 3 = severe pruritus; incidence of PONV, antiemetic and antipruritic would be used within 24 hours.

Sample size calculations were based on data ( 4.8 mean \pm 2.8 standard deviation pain scores on movement) from a pilot study involving ITM after CD. We considered a reduction in the mean intensity pain score of $1.8 \mathrm{~mm}$ as clinically significant. A sample size analysis, using 2-tailed Student t-test with power $=0.9$ and $\alpha=0.05$ estimated a sample size of 51 per group.

The continuous data with normal distribution were analyzed by analysis of variance (ANOVA) followed by the Tukey test for post hoc analysis, if necessary. The discrete or continuous data without normal distribution and ordinal data were analyzed by Kruskal-Wallis test followed by the Mann-Whitney test for post hoc analysis, if necessary. Comparison between two evaluations for quantitative variables was performed by using the non-parametric Wilcoxon's test (paired samples). For categorical data were used the Chi-square test to detect differences among groups and Fisher's exact test to detect the difference among the groups. For all analyses, the p-value was set at 0.05 for statistical significance.

\section{Results}

Two hundred and forty-three patients were sampled for the study. Two hundred and one patients were randomized to the study. Two patients in the group 0.075 were excluded due to loss of follow-up, one was excluded due to postoperative complication (abdominal wall hematoma) and another case for allergy to ketoprofen (angioedema). Five patients were excluded due to data missing (three patients in the group 0.15 , one in the group 0.01 and, another in the group 0.075). The flow chart of recruitment, allocation, follow-up, analysis of patients, and causes of exclusion is shown in Figure 1.

The groups were homogeneous regarding age, body mass index, ASA physical status class, parity, gestational age, previous $\mathrm{CD}$ and fentanyl use during surgery and duration of operation (Table 1).

The three groups showed similar pain intensity at rest and on movement, in 6 hours and 24 hours postoperatively. The pain intensity on movement was significantly higher than at rest in the groups ( $\mathrm{p}<0.001$, Wilcoxon's test). There were no statistical differences among groups regarding tramadol use. The overall satisfaction (satisfied/very) with control relief was $73.8 \%, 82.5 \%$ and $87.8 \%$ in 


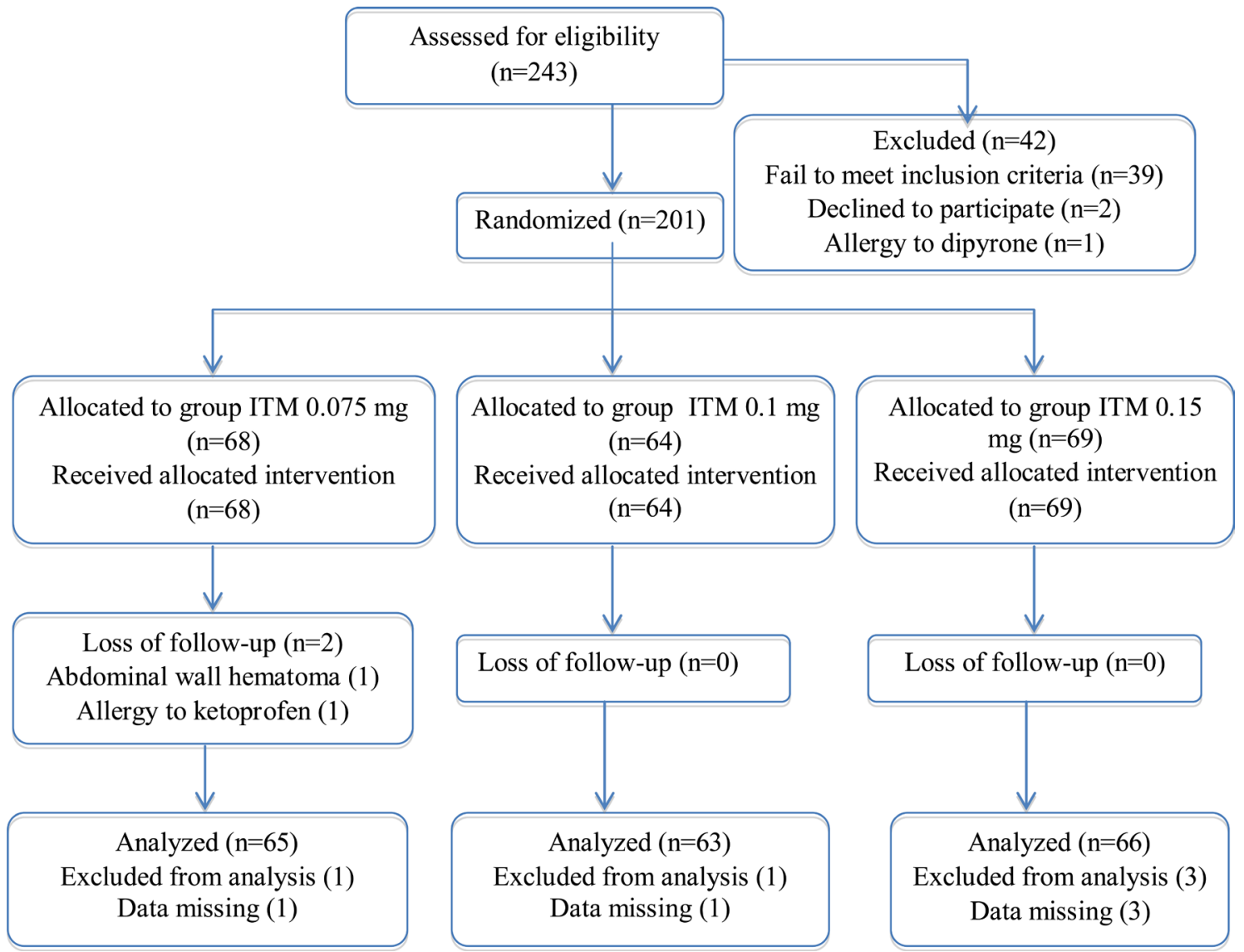

Figure 1. Flow chart of the study.

Table 1. Maternal demographic variables.

\begin{tabular}{|c|c|c|c|}
\hline & $\begin{array}{c}\text { Group } 0.075 \\
n=65\end{array}$ & $\begin{array}{c}\text { Group } 0.1 \\
n=63\end{array}$ & $\begin{array}{c}\text { Group } 0.15 \\
n=66\end{array}$ \\
\hline Age (years)* & $26.7 \pm 6.3$ & $26.4 \pm 5.7$ & $26.6 \pm 6.0$ \\
\hline $\operatorname{BMI}\left(\mathrm{kg} / \mathrm{m}^{2}\right)^{*}$ & $31.6 \pm 5.7$ & $30.1 \pm 5.1$ & $30.5 \pm 5.9$ \\
\hline ASA physical status class (I/II/III) & $30 / 32 / 2$ & $30 / 27 / 4$ & $41 / 19 / 5$ \\
\hline Gestational age (weeks)* & $38.7 \pm 2.3$ & $38.7 \pm 2.2$ & $38.9 \pm 1.9$ \\
\hline Parity $(0 / 1 / \geq 2)$ & $14 / 31 / 19$ & $11 / 30 / 21$ & $12 / 27 / 26$ \\
\hline Previous cesarean delivery $(\mathrm{n}, \%)$ & $29(44)$ & $34(53)$ & $31(46)$ \\
\hline Fentanyl use during surgery $(\mathrm{mg})^{\star}$ & $2.9 \pm 14.6$ & $2.3 \pm 10.5$ & $1.8 \pm 11$ \\
\hline Duration of surgery $(\min )^{\star}$ & $63.2 \pm 9.2$ & $64.1 \pm 16.7$ & $61.6 \pm 11.4$ \\
\hline
\end{tabular}

${ }^{*}$ Mean \pm standard deviation; BMI (body mass index); ASA (American Society of Anesthesiologists). 0.075 intrathecal morphine $0.075 \mathrm{mg}, 0.1$ intrathecal morphine $0.1 \mathrm{mg}, 0.15$ intratechal morphine $0.15 \mathrm{mg}$. All comparisons: $\mathrm{p}>0.05$.

the groups $0.075,0.1$ and 0.15 , respectively. However there were no significant differences among the groups (Table 2).

There was no significant difference for the incidence of nausea among dose groups. One patient in the group 0.075 , another in the group 0.1 and 4 in the 
group 0.1 presented vomiting. The percentage of patients who required treatments for PONV over the first 24 hours had no difference among three different doses of ITM morphine.

The moderate to severe pruritus were progressively higher: group 0.075 (13.8\%), group $0.1(20.5 \%)$ and group $0.15(24.1 \%)$ as the intrathecal doses of morphine increased, but there were no significant differences (Table 3). None of the patients suffered from respiratory depressions in this study.

\section{Discussion}

ITM has been widely used for analgesia after CD because of its prolonged

Table 2. Pain scores (NRS), analgesic use and overall satisfaction with pain relief after cesarean delivery.

\begin{tabular}{cccc}
\hline & $\begin{array}{c}\text { Group 0.075 } \\
\mathrm{n}=65\end{array}$ & $\begin{array}{c}\text { Group 0.1 } \\
\mathrm{n}=63\end{array}$ & $\begin{array}{c}\text { Group 0.15 } \\
\mathrm{n}=66\end{array}$ \\
\hline NRS - Rest at 6 h & $1.2 \pm 2.1$ & $1.4 \pm 1.8$ & $1.3 \pm 2.3$ \\
NRS - On movement at 6 h & $3.9 \pm 2.5^{*}$ & $4.2 \pm 2.3^{*}$ & $3.6 \pm 2.8^{*}$ \\
NRS - Rest at 24 h & $1.9 \pm 2.5$ & $1.8 \pm 2.3$ & $1.3 \pm 2.2$ \\
NRS - On movement at 24 h & $4.5 \pm 2.5^{* *}$ & $4.5 \pm 2.8^{* *}$ & $4.2 \pm 2.5^{* *}$ \\
Intravenous tramadol used 0 - 24 h & $10(13.8)$ & $3(4.7)$ & $7(10.6)$ \\
Overall satisfaction with pain relief & & & \\
Very unsatisfied/unsatisfied & $17(26.2)$ & $11(17.5)$ & $8(12.2)$ \\
Satisfied/very satisfied & $48(73.8)$ & $52(82.5)$ & $58(87.8)$ \\
\hline
\end{tabular}

NRS: numeric rating scale; Data are expressed as Mean \pm standard deviation or number (\%). 0.075 intrathecal morphine $0.075 \mathrm{mg}, 0.1$ intrathecal morphine $0.1 \mathrm{mg}, 0.15$ intratechal morphine $0.15 \mathrm{mg}$. All comparisons: $\mathrm{p}>0.05$. ${ }^{*} \mathrm{p}<0.001$ versus NRS at rest in 6 hours and ${ }^{* *} \mathrm{p}<0.001$ versus NRS at rest in 24 hours (Wilcoxon's test).

Table 3. Side effects after cesarean delivery in 24 hour postoperation.

\begin{tabular}{cccc}
\hline & $\begin{array}{c}\text { Group 0.075 } \\
\mathrm{n}=65\end{array}$ & $\begin{array}{c}\text { Group 0.1 } \\
\mathrm{n}=63\end{array}$ & $\begin{array}{c}\text { Group 0.15 } \\
\mathrm{n}=66\end{array}$ \\
\hline Nausea & $7(10.7)$ & $9(14.2)$ & $6(9.0)$ \\
Vomiting & $1(1.5)$ & $1(1.5)$ & $4(6)$ \\
Antiemetic use & $6(9.2)$ & $7(11.1)$ & $8(12.1)$ \\
Pruritus & & & \\
Absent & $27(41)$ & $25(39.6)$ & $26(39.3)$ \\
Mild & $29(44.6)$ & $25(39.6)$ & $24(36.3)$ \\
Moderate & $13(19.6)$ & $9(14.2)$ & $8(12.2)$ \\
Severe & $1(1.5)$ & $4(6.3)$ & $3(4.5)$ \\
Antipruritic use & $2(3)$ & $5(7.9)$ & $5(7.5)$ \\
\hline
\end{tabular}

Data are expressed as numbers (\%). 0.075 intrathecal morphine $0.075 \mathrm{mg}, 0.1$ intrathecal morphine $0.1 \mathrm{mg}$, 0.15 intratechal morphine $0.15 \mathrm{mg}$. All comparisons: $\mathrm{p}>0.05$ 
postoperative analgesic effects. A survey conducted in the U.S. $79 \%$ of the anesthesiologists using ITM for pain control after CD [3]. However, intrathecal opioids might result in side effects such as nausea, vomiting, pruritus, sedation, and respiratory depression [11]. In the context, the promotion of adequate analgesia with minimal side effects is essential in obstetrics.

The pain assessment is complex and concerns the influences of emotional factors, cognitive, cultural, and ethnic. The well-known visual analog scale (VAS) and numeric rating scale (NRS) for assessment of pain intensity agree well and are equally sensitive in assessing acute pain after surgery. The NRS is more practical than a VAS and easier to understand for the most people and taking into account that acute pain during movement (dynamic pain) is more important than pain at rest. Therefore, we use the NRS as a method of evaluation of pain at rest and on movement in this study [13].

The intensity of pain was similar among the groups in the doses of 0.075, 0.1 and $0.15 \mathrm{mg}$ of ITM in our study. However, the pain scores on movement were higher than at rest in 6 hours and 24 hours in the groups ( $\mathrm{p}<0.001$, Wilcoxon's test). The pain scores at rest are in line with the goal advocated by The Royal College of Anaesthetists [14], but not on movement.

Recently Sultan et al. in their meta-analysis compared low ITM doses (0.05 $0.1 \mathrm{mg})$ with high doses $(>0.1-0.25 \mathrm{mg})$ and obtained a prolongation of analgesia at higher doses [8]. Wong et al. studied 240 patients and reported that $0.2 \mathrm{mg}$ ITM provided better analgesia but with more nausea and more utilization of antiemetic compared with morphine $0.1 \mathrm{mg}$ [15]. Girgin et al. in their study with only 95 patients randomized in 5 groups did not identify any difference in analgesia with use of ITM ( 0.1 to $0.4 \mathrm{mg}$ ) but identified pruritus-dependent dose [16]. Weigl al. found that intrathecal combination of fentanyl $(0.025 \mathrm{mg})$ and morphine $(0.1 \mathrm{mg})$ might provide better perioperative analgesia than morphine alone in CD. However, there was an increase in PONV [17]. And Berger et al. compared low ITM doses $(0.05,0.1$ or $0.15 \mathrm{mg})$ in patients that received ketorolac during $\mathrm{CD}$ and in 24 hours postoperation. They concluded that $0.05 \mathrm{mg}$ might produce similar analgesia that produced by either 0.1 or $0.15 \mathrm{mg}$ [18]. In our study, the use of dexamethasone (only intraoperatively), dipyrone and ketoprofen (intraoperatively and postoperatively at regular times) can have mitigated the differences of pain scores among the three different doses of ITM (multimodal analgesia) [19] [20].

Tramadol binds to $\mu$ opioid receptors and also inhibits the reuptake of norepinephrine and serotonin which leads to pain relief. Only 13.8\% (group 0.075), $4.7 \%$ (group 0.1 ) and $10.6 \%$ (group 0.15 ) of patients requested tramadol for postoperative pain. Interestingly, although most patients in all three groups had moderated pain on movement, this did not reflect any increase in the use of tramadol, probably because immediately after the evaluation, patients returned to rest in their beds and their pain diminished. This fact could lead us to conjecture that perhaps it would be better to evaluate the pain when in ambulation 
than when moving from supine to sitting on the bed.

The overall satisfaction (satisfied/very) with control relief was 73.8, 82.5 and $87.8 \%$ in the groups $0.075,0.1$ and 0.15 , respectively. However there were no significant differences among the groups. Perhaps there would be a statistical difference with the increase in the sample.

The incidence of PONV in patients who received an intrathecal opiate is $60 \%$ $80 \%$ [21]. Koju et al. used $0.2 \mathrm{mg}$ of ITM and observed that women receiving 4 mg prophylactic ondansetron had an incidence of $8 \%$ of PONV, whereas those receiving placebo the incidence was 56\% [21]. While Imeh et al. found an incidence of $9.3 \%$ and $37 \%$ of PONV when they used dexamethasone plus ondansetron prophylactically compared to dexamethasone in patients who received $0.2 \mathrm{mg}$ of ITM [22]. In our study, the incidence of PONV was low in three groups: $12.2 \%, 15.7 \%$ and $15 \%$, probably the use of dexamethasone and ondansetron may have contributed favorably to these results.

Spinal opioid-induced pruritus is an unwanted pruritus sensation that is often seen in obstetric patients with an incidence of $20 \%$ to $100 \%$ [23]. In the meta-analysis performed by George et al. the use of prophylactic 5-HT3 receptor antagonists were ineffective in reducing the incidence of pruritus, but they greatly reduced the severity and the need for treatment of pruritus [24]. Recently two papers has been published which analyzed the use of prophylactic ondansetron in parturients, and showed conflicting results. In one study, pruritus was reduced by $72 \%$, while in another study there was no reduction in pruritus, both compared to placebo [21] [25]. In our study, there were no differences in the incidence of pruritus and use of antipruritic medication (promethazine). It was observed that an incidence of pruritus around $60 \%$, but the intensity (moderate to severe) of the pruritus was low, ranging from $14 \%$ to $24 \%$ in the groups. Also, less than $8 \%$ of patients requested antipruritic medication.

Limitations of the study: the study was conducted at a single center and involved a relatively small number of patients; this may impact on the generalizability of the results of this study. The calculation of the power of the current study was based on a pilot study and not a large randomized clinical trial. The use of tramadol as an analgesic rescue (important secondary endpoint) via PCA could better reflect the consumption of this painkiller.

\section{Conclusion}

In conclusion, we compared results when $0.075,0.1$ or $015 \mathrm{mg}$ of ITM was added to hyperbaric bupivacaine $12.5 \mathrm{mg}$. Our findings show that in cases of the elective $\mathrm{CD}, 0.075 \mathrm{mg}$ of ITM produces postoperative analgesia of similar quality that provided by 0.1 or $0.15 \mathrm{mg}$ ITM with no difference in the IV tramadol use, overall satisfaction with pain relief and side effects. However, the pain scores on movement were higher than at rest in 6 hours and 24 hours in the three groups. Despite of several results of different studies on the doses of morphine for analgesia, there is no recommendation for the optimal dose of ITM which produces 
adequate analgesia with minimal side effects. Therefore the patients who submitted the CD should have a multimodal analgesia approach that includes: ITM, anti-inflammatory agents and access to additional systemic analgesic if necessary because a portion of patients may feel moderate to severe pain, especially on movement.

\section{Conflicts of Interest}

The authors declare no conflicts of interest regarding the publication of this paper.

\section{References}

[1] Ministry of Health. DATASUS. Report of Live Births in Brazil (2015). http://tabnet.datasus.gov.br/cgi/tabcgi.exe?sinasc/cnv/nvuf.def

[2] Betrán, A.P., Ye, J., Moller, A.-B., Zhang, J., Gülmezoglu, A.M. and Torloni, M.R. (2016) The Increasing Trend in Caesarean Section Rates: Global, Regional and $\mathrm{Na}-$ tional Estimates: 1990-2014. PLOS ONE, 1, e01483431. https://doi.org/10.1371/journal.pone.0148343

[3] Aiono-Le Tagaloa, L., Butwick, A.J. and Carvalho, B. (2009) A Survey of Perioperative and Postoperative Anesthetic Practices for Cesarean Delivery. Anesthesiology Research and Practice, 2009, 510642. https://doi.org/10.1155/2009/510642

[4] Flood, P. and Rollins, M.D. (2015) Anesthesia for Obstetrics. In: Miller, R.D., Ed., Miller's Anesthesia, 8th Edition, Elsevier Churchill Livingstone, Philadelphia, 2328-2358.

[5] Qiu, M.T., Lin, F.Q., Fu, S.K., et al. (2012) Combination of Low-Dose Bupivacaine and Opioids Provide Satisfactory Analgesia with Less Intraoperative Hypotension for Spinal Anesthesia in Cesarean Section. CNS Neuroscience \& Therapeutics, 18 426-432. https://doi.org/10.1111/j.1755-5949.2012.00306.x

[6] Seljogi, D., Wolf, A.P., Scheffer, G.J., Van Geffen, G.J. and Bruhn, J. (2016) Correlation of Bupivacaine 0.5\% Dose and Conversion from Spinal Anestesia to General Anesthesia in Cesarean Sections. Acta Anaesthesiologica Belgica, 67, 36-42.

[7] Carvalho, B., Cohen, S.E., Lipman, S.S., Fuller, A., Mathusamy, A.D. and Macario, A. (2005) Patient Preferences for Anesthesia Outcomes Associated with Cesarean Delivery. Anesthesia \& Analgesia, 101, 1182-1187. https://doi.org/10.1213/01.ane.0000167774.36833.99

[8] Sultan, P., Halpern, S.H., Pushpanathan, E., Patel, S. and Carvalho, B. (2016) The Effect of Intrathecal Morphine Dose on Outcomes after Elective Cesarean Delivery: A Meta-Analysis. Anesthesia \& Analgesia, 123, 154-164. https://doi.org/10.1213/ANE.0000000000001255

[9] Bujedo, B.M. (2014) Spinal Opioid Bioavailability in Postoperative Pain. Pain Practice, 14, 350-364. https://doi.org/10.1111/papr.12099

[10] Patel, N., Bryant, A., Duncan, K., Kukreja, P. and Powell, M.F. (2017) Cost Comparison of Intrathecal Morphine to Intravenous Patient-Controlled Analgesia for the First 24 h Post-Cesarean Delivery: A Retrospective Cohort Study. Journal of Anesthesia, 31, 44-50. https://doi.org/10.1007/s00540-016-2263-5

[11] Gehling, M. and Tryba, M. (2009) Risks and Side-Effects of Intrathecal Morphine Combined with Spinal Anaesthesia: A Meta-Analysis. Anaesthesia, 64, 643-651. https://doi.org/10.1111/j.1365-2044.2008.05817.x

[12] Aldrete, J.A. (1995) The Post-Anesthetic Recovery Score Revisited. Journal of Clin- 
ical Anesthesia, 7, 89-91. https://doi.org/10.1016/0952-8180(94)00001-K

[13] Breivik, H., Borchgrevink, P.C., Allen, S.M., et al. (2008) Assessment of Pain. British Journal of Anaesthesia, 101, 17-24. https://doi.org/10.1093/bja/aen103

[14] Pickering and Holdcraft (2006) Pain Relief after Cesarean Section. In: Kinsella, M., Ed., Raising the Standard: A Compendium of Audit Recipes. 2nd Edition, Royal College of Anaesthetists, London, 168-169.

[15] Wong, J.Y., Carvalho, B. and Riley, E.T. (2013) Intrathecal Morphine 100 and 200 $\mu \mathrm{g}$ for Post-Cesarean Delivery Analgesia: A Trade-Off between Analgesic Efficacy and Side Effects. International Journal of Obstetric Anesthesia, 22, 36-41. https://doi.org/10.1016/j.ijoa.2012.09.006

[16] Girgin, N.K., Gurbet, A., Turker, G., Aksu, H. and Gulhan, N. (2008) Intrathecal Morphine in Anesthesia for Cesarean Delivery: Dose-Response Relationship for Combinations of Low Dose Intrathecal Morphine and Spinal Bupivacaine. Journal of Clinical Anesthesia, 20, 180-185. https://doi.org/10.1016/j.jclinane.2007.07.010

[17] Weigl, W., Bierylo, A., Krzmien-wiczynska, S., Kolacz, M. and Dabrowski, M.J. (2017) Perioperative Analgesia after Intrathecal Fentanyl and Morphine or Morphine Alone for Cesarean Section: A Randomized Controlled Study. Medicine (Baltimore), 96, e8892. https://doi.org/10.1097/MD.0000000000008892

[18] Berger, J., Gonzalez, A., Hopkins, A., Alshaeri, T., Jeon, D., Wang, S., Amdur, R.L. and Smiley, R. (2016) Dose-Response of Intrathecal Morphine When Administered with Intravenous Ketorolac for Post-Cesarean Analgesia: A Two-Center, Prospective, Randomized, Blinded Trial. International Journal of Obstetric Anesthesia, 28, 3-11. https://doi.org/10.1016/j.ijoa.2016.08.003

[19] Booth, J.L., Harris, L.C., Eisenach, J.C. and Pan, P.H. (2016) A Randomized Controlled Trial Comparing Two Multimodal Analgesic Techniques in Patients Predicted to Have Severe Pain after Cesarean Delivery. Anesthesia \& Analgesia, 122, 1114-1119. https://doi.org/10.1213/ANE.0000000000000695

[20] Carvalho, B. and Butwick, A.J. (2017) Post-Cesarean Delivery Analgesia. Best Practice \& Research: Clinical Anaesthesiology, 31, 69-79.

https://doi.org/10.1016/j.bpa.2017.01.003

[21] Koju, R.B., Gurung, B.S. and Dongol, Y. ( 2015) Prophylactic Administration of Ondansetron in the Prevention of Intrathecal Morphine-Induced Pruritus and Post-Operative Nausea and Vomiting in Patients Undergoing a Cesarean Section. BMC Anesthesiology, 15, 18. https://doi.org/10.1186/1471-2253-15-18

[22] Imeh, A., Olaniyi, O., Simeon, O. and Omotola, O. (2014) Dexamethasone versus a Combination of Dexamethasone and Ondansetron as a Prophylactic Antiemetic in Patients Receiving Intrathecal Morphine for Caesarean Section. African Health Sciences, 14, 453-459. https://doi.org/10.4314/ahs.v14i2.23

[23] Ko, M.C. (2015) Neuraxial Opioid-Induced Itch and Its Pharmacological Antagonism. Handbook of Experimental Pharmacology, 226, 315-335. https://doi.org/10.1007/978-3-662-44605-8_17

[24] George, R.B., Allen, T.K. and Habib, A.S. ( 2009) Serotonin Receptor Antagonists for the Prevention and Treatment of Pruritus, Nausea, and Vomiting in Women Undergoing Cesarean Delivery with Intrathecal Morphine: A Systematic Review and Meta-Analysis. Anesthesia \& Analgesia, 109, 174-82. https://doi.org/10.1213/ane.0b013e3181a45a6b

[25] Kung, A.T., Yang, X., Li, Y., Vasudevan, A., Pratt, S. and Hess, P. (2014) Prevention versus Treatment of Intrathecal Morphine-Induced Pruritus with Ondansetron. International Journal of Obstetric Anesthesia, 23, 222-226. https://doi.org/10.1016/j.ijoa.2014.04.007 